\title{
The pmk1-like mitogen-activated protein kinase
from Lecanicillium (Verticillium) fungicola is not
required for virulence on Agaricus bisporus
Patrick D. Collopy, ${ }^{1 \dagger}$ Richard C. Amey, ${ }^{1}$ Martin J. Sergeant,
Michael P. Challen, ${ }^{2}$ Peter R. Mills, ${ }^{2}$ Gary D. Foster ${ }^{1}$ and Andy M. Bailey ${ }^{1}$
$\begin{aligned} & { }^{1} \text { School of Biological Sciences, University of Bristol, Bristol BS8 1UG, UK } \\ & \begin{array}{l}\text { Correspondence } \\ \text { Andy M. Bailey } \\ \text { andy.bailey@bristol.ac.uk }\end{array}\end{aligned}{ }^{2}$ Warwick HRI, University of Warwick, Wellesbourne, Warwick CV35 9EF, UK \\ In plant-pathogenic fungi, the pmk1 mitogen-activated protein kinase (MAPK) signalling pathway plays an essential role in regulating the development of penetration structures and the sensing of host-derived cues, but its role in other pathosystems such as fungal-fungal interactions is less clear. We report the use of a gene disruption strategy to investigate the pmk1-like MAPK, Lf pmk1 in the development of Lecanicillium fungicola (formerly Verticillium fungicola) infection on the cultivated mushroom Agaricus bisporus. Lf pmk1 was isolated using a degenerate PCR-based approach and was shown to be present in a single copy by Southern blot analysis. Quantitative RT-PCR showed the transcript to be fivefold upregulated in cap lesions compared with pure culture. Agrobacterium-mediated targeted disruption was used to delete a central portion of the $L f$ pmk1 gene. The resulting mutants showed normal symptom development as assessed by A. bisporus mushroom cap assays, sporulation patterns were normal and there were no apparent changes in overall growth rates. Our results indicate that, unlike the situation in fungal-plant \\ Received 8 September 2009 Revised 15 January 2010 Accepted 21 January 2010 pathogens, the $p m k 1$-like MAPK pathway is not required for virulence in the fungal-fungal interaction between the $L$. fungicola pathogen and $A$. bisporus host. This observation may be of wider significance in other fungal-fungal and/or fungal-invertebrate interactions.
}

\section{INTRODUCTION}

Lecanicillium fungicola (Pruess) Hassebrauk is the causal agent of dry bubble disease of the cultivated button mushroom Agaricus bisporus (Lange) Imbach. It is one of the most serious pathogens of this crop and is worldwide in distribution. The disease manifests itself in three different symptoms: dry bubble, stipe blow-out and cap-spotting diseases (Mills et al., 2008). Disease outbreaks remain a serious threat to the mushroom industry and can devastate crops where successful management of this disease mainly relies on good cultural practices and strict sanitation. The broad-spectrum azole fungicide prochloraz-manganese has sometimes been used to control infections; however, resistance is becoming more common within the pathogen population, which limits the usefulness of this product (Bonnen and Hopkins, 1997). Other fungicides are less effective or impact on the host fungus (ChrysayiTokousbalides et al., 2007) and may give concerns regard-

tPresent address: Genetics Department, Dartmouth Medical School, Hanover, NH 03755, USA

Abbreviations: DI, deionized (water); MAPK, mitogen-activated protein kinase; MAPKK, MAPK kinase; MAPKKK, MAPKK kinase; MM, minimal medium; PDA, potato dextrose agar; Q-PCR, quantitative RT-PCR. ing residues in the crop or in the spent mushroom compost. To date, no other acceptable means of chemical control for L. fungicola have been marketed, probably due to prohibitive development and licensing costs, whilst difficulties involved with breeding of A. bisporus have prevented disease-resistant strains from being developed. Although formerly known as Verticillium fungicola, the taxonomy of these fungi has recently been revised, with the group renamed Lecanicillium (Zare \& Gams, 2001, 2008; Amey et al., 2007), showing it to be more closely related to the insect pathogenic fungi, such as L. longisporum (formerly V. lecanii), and nematode pathogens, such as those within the genus Haptocillium (e.g. V. balanoides). Indeed, there are reports of $L$. fungicola being isolated from other invertebrates such as nematodes (Gené et al., 2005).

Many fungal pathogens are sensitive to chemical and physical cues from their host surfaces and these cues often promote the formation of penetration structures, such as appressoria. Mitogen activated protein kinases (MAPKs) are a family of eukaryotic serine/threonine protein kinases (Kültz, 1998) involved in the transduction of extracellular signals, growth regulation and differentiation processes (Nishida \& Gotoh, 1993; Dickman \& Yarden, 1999; Schaeffer \& Weber, 1999). MAPK kinases (MAPKKs) 
activate MAPKs, with MAPKK kinases (MAPKKKs) activating MAPKKs. These MAPKKK-MAPKK-MAPK cascades are conserved in many organisms (Xu, 2000), suggesting the probable presence of similar MAPK homologues in L. fungicola. The pathways have been intensively studied in model fungi such as Aspergillus nidulans or Neurospora crassa, with genome sequences revealing the presences of three or occasionally four MAPK genes for most ascomycete fungi.

Pathogenesis-related functions of MAPKs have been demonstrated in a number of plant-pathogenic fungi, including Magnaporthe grisea (Xu \& Hamer, 1996; Xu et al., 1998), Ustilago maydis (Muller et al., 1999; Mayorga \& Gold, 2001), Cochliobolus heterostrophus (Lev et al., 1999), Botrytis cinerea (Zheng et al., 2000), Colletotrichum lagenarium (Takano et al., 2000), Fusarium oxysporum (Di Pietro et al., 2001), Claviceps purpurea (Mey et al., 2002) and Cryphonectria parasitica (Park et al., 2004). M. grisea is the most intensively studied of the plant pathogenic ascomycetes, with three MAPK homologues being characterized (Xu, 2000; Zhao et al., 2007).

It has been suggested that the MAPK family of genes has probably co-evolved with their targets, scaffold proteins and kinases that activate them (Lev et al., 1999; Park et al., 2003), so the function of a MAPK gene in one species may be slightly different from one with a similar sequence in another species. For example, the $p m k 1$ gene in M. grisea has a specific role in forming large, melanized appressoria, whereas in C. heterostrophus, the equivalent gene homologue, chkl, has a wider set of developmental roles and a smaller role in appressoria formation (Lev \& Horwitz, 2003). Despite these small differences in effectors, there is a general phenomenon that, amongst fungal plant pathogens, pmkl homologues are essential for virulence and that gene disruption compromises pathogenicity. Whether the same is true for pathogens of other hosts is less clear. In the animal pathogen Cryptococcus neoformans, impairment of this signalling pathway has only a small impact on virulence (Clarke et al., 2001). Infection of immune-depressed mice with the pmk1-deficient F. oxysporum showed normal infection in these mammals, despite eliminating virulence against their normal plant hosts (Ortoneda et al., 2004). The role of a MAPK signal transduction pathway in disease development of fungalfungal interactions is largely unresolved. In this study, a pmk1-like MAPK homologue from L. fungicola was cloned, characterized and used to determine expression in $L$. fungicola infections of $A$. bisporus.

\section{METHODS}

Fungal culture. All experiments were performed with L. fungicola isolate 150-1, which was originally isolated from a diseased mushroom (Mills et al., 2008). Cultures for experimental purposes were grown as described previously (Amey et al., 2002) on CzapekDox agar (CDA) potato dextrose agar (PDA) supplemented, when appropriate, with $650 \mu \mathrm{g}$ hygromycin $\mathrm{B} \mathrm{ml}^{-1}$, or using L. fungicola minimal medium (MM; Calonje et al., 1997) with the addition of $0.1 \%$ A. bisporus cell wall material (ACWM). Agaricus cell wall extracts were prepared by using the method described by NovaesLedieu \& Mendoza (1981): button mushrooms were homogenized in a Waring blender, the homogenate was centrifuged to harvest the cell wall material and the pellet was then washed twice in deionized (DI) water, twice in $10 \%(\mathrm{w} / \mathrm{v})$ sucrose and twice in $1 \mathrm{M} \mathrm{NaCl}$. Two further washes with DI water were performed before the precipitate was freeze-dried and ground to a fine powder.

Nucleic acid manipulations. L. fungicola genomic DNA was isolated essentially as described by Keon \& Hargreaves (1998) and used for Southern analysis. Genomic DNA $(5 \mu \mathrm{g})$ of wild-type, disruptants and a control transformant was digested with BglII or with $S a c I$ and separated by gel electrophoresis. Gels were denatured and DNA was blotted onto Hybond- $\mathrm{N}^{+}$membranes. These were probed with a ${ }^{32} \mathrm{P}$-labelled dCTP fragment of the right flanking sequence that was generated by PCR using primers $5^{\prime}$ CGTGAAGTGGGTTCAGGAAAA-3' and $5^{\prime}$-AACACCCCTACCTCGAGCCAT-3'. Hybridizations were carried out according to the method described by Amey et al. (2002). Plasmid DNA was purified using the Promega wizard SV mini-prep kit.

PCR was performed on a PTC-100 thermocycler (MJ Research) in $20 \mu \mathrm{l}$ reaction volumes. Cycling parameters for degenerate primers were: 1 cycle of $94{ }^{\circ} \mathrm{C} 2 \mathrm{~min}$; 30 cycles of $94{ }^{\circ} \mathrm{C} 30 \mathrm{~s}$, $50{ }^{\circ} \mathrm{C} 30 \mathrm{~s}, 72{ }^{\circ} \mathrm{C} 30 \mathrm{~s} ; 1$ cycle of $72{ }^{\circ} \mathrm{C} 4 \mathrm{~min}$. To permit amplification of longer products, the annealing temperature (55$\left.60{ }^{\circ} \mathrm{C}\right)$, extension time $(2 \mathrm{~min})$ and number of cycles $(n=35)$ were modified.

RNA extraction and quantitative RT-PCR (Q-PCR). Total RNA was extracted from $L$. fungicola agar cultures and from lesions formed on A. bisporus sporophores using Tri reagent (Invitrogen). RNA $(1 \mu \mathrm{g})$ was digested in $10 \mu \mathrm{l}$ volumes with $1 \mu \mathrm{l}$ DNase Q and $1 \mu \mathrm{l}$ $10 \times$ DNase Q buffer (Promega) for $30 \mathrm{~min}$ at $37{ }^{\circ} \mathrm{C}$. To stop the reaction, $1 \mu \mathrm{l}$ DNase Q stop solution (Promega) was added to the mixture and heated to $65{ }^{\circ} \mathrm{C}$ for $10 \mathrm{~min}$. DNase-treated RNA $(1 \mu \mathrm{g})$ was converted to cDNA using the ThermoScript RT-PCR System (Invitrogen) with random hexamers (Amersham), following the manufacturer's instructions, except for the following modifications: random hexamers together with RNA were heated $\left(65^{\circ} \mathrm{C}, 10 \mathrm{~min}\right)$ and cooled on ice before the $50{ }^{\circ} \mathrm{C}$ incubation step, which was increased to $1 \mathrm{~h} 30 \mathrm{~min}$. At the end of the reaction, cDNA was diluted to $10 \mathrm{ng} \mu \mathrm{l}^{-1}$ by the addition of $80 \mu \mathrm{H}_{2} \mathrm{O}$ (assumed $100 \%$ conversion of RNA to cDNA). Primer pairs for the $L f p m k 1$ gene $\left(5^{\prime}\right.$ GATGTCGTCGGCGAAGGT-3'/5' -TGGCCTGATGGTTTGTGGAT$\left.3^{\prime}\right)$ and $18 \mathrm{~S}$ (5'-CAACGGGTAACGGAGGGTTA-3'/5' -TGCTGCCTTCCTTGGATGTAG-3') were designed using ABI Primer Express (v 2.0). The $18 \mathrm{~S}$ primers were tested against $A$. bisporus $\mathrm{CDNA}$ and did not yield any significant values. Q-PCR was carried out using the ABI TaqMan $9700 \mathrm{HT}$ with standard cycling conditions ( 40 cycles of $95{ }^{\circ} \mathrm{C}$ for $15 \mathrm{~s}$ followed by $1 \mathrm{~min}$ at $\left.60^{\circ} \mathrm{C}\right)$. Reaction mixtures $(15 \mu \mathrm{l})$ comprised $7.5 \mu \mathrm{l} \mathrm{SYBR}$ Green master mix (Eurogentech), $1 \mu \mathrm{M}$ each primer and $2 \mu \mathrm{l}(20 \mathrm{ng}) \mathrm{cDNA}$. Because of the large amount of $18 \mathrm{~S}$ RNA present, only $5 \mathrm{ng}$ cDNA was used. Three independent biological replicates each from $L$. fungicola agar cultures and $A$. bisporus lesions were analysed. Two (technical replicate) reactions were carried out for each sample and also for each standard, with the mean of two replicates being used in subsequent calculations. Standard curves were generated for each gene (primer combination) using fourfold dilutions of a mixture of appropriate cDNA samples. TaqMan SDS software (v 2.1) was used to obtain the cycle threshold $\left(C_{\mathrm{t}}\right)$ for each sample and to calculate relative values based on appropriate standard curves, which were imported into Microsoft Excel for subsequent analysis. Relative values were normalized against $18 \mathrm{~S}$ values to indicate relative gene expression. 
Isolation of the $\boldsymbol{L f}$ pmk1 gene. To obtain the full-length genomic clone, the lambda-BlueSTAR genomic library described by Amey et al. (2003) was screened in duplicate by probing with the degenerate PCR-generated gene fragment obtained using primers Map3 $\left(5^{\prime}\right.$ GAYGAYCAYTGYCARTAYTTYAT-3') and Map7 (5'-TTDATNCCRTARTARTCYTCCAT-3'), designed using conserved regions of pmkl-like MAPKs from various filamentous fungi. Library screening under high-stringency conditions and routine procedures was carried out using standard protocols. Sequence data were analysed using Sequencher software (Gene Codes). The BLASTnr algorithm was used to search DNA and protein databases at the National Center for Biotechnology Information. Multiple sequence alignments were prepared using CLUSTAL_X and neighbour-joining, bootstrapped trees were produced using MEGA3.1 (Kumar et al., 2004).

Knockout plasmid construction. The disruption cassette was constructed in pZEJ (Johnson, 2006), a mini-binary vector based on pGREENII (Hellens et al., 2000), containing a hygromycin resistance cassette within the T-DNA. The $1141 \mathrm{bp}$ upstream targeting region (left arm) was amplified by PCR from a plasmid template and restriction sites for ClaI and EcoRI were incorporated into the primers for directional cloning upstream of the Hygromycin cassette in pZEJ. In the same manner, the 1089 bp downstream targeting region (right arm) was amplified but included restriction sites for SpeI and NotI to yield the transformation plasmid pZMK37. Concurrently, an 826 bp downstream targeting region (right arm) with the same included restriction sites was constructed to yield transformation plasmid pZMK38.

Agrobacterium (Ag.) tumefaciens-mediated transformation. Transformation of L. fungicola 150-1 with either pZMK37 or pZMK38 was performed essentially as described by Amey et al. (2002) using the pGreen/pSoup system (Hellens et al., 2000). Briefly, $100 \mu \mathrm{l}$ of an L. fungicola $150-1$ spore suspension $\left(10^{6}\right.$ spores $\left.\mathrm{ml}^{-1}\right)$ was mixed with $100 \mu \mathrm{l} \mathrm{Ag}$. tumefaciens and plated onto cellophane disks on induction medium (Hooykaas et al., 1979). Following 2 days co-cultivation, cellophane disks were transferred to PDA supplemented with $200 \mu \mathrm{g}$ cefotaxime $\mathrm{ml}^{-1}$ and $650 \mu \mathrm{g}$ hygromycin $\mathrm{B} \mathrm{ml} \mathrm{m}^{-1}$. After a further 4 days, transformants were subcultured onto PDA with $650 \mu \mathrm{g}$ hygromycin $\mathrm{B} \mathrm{ml}^{-1}$ alone and incubated at $20^{\circ} \mathrm{C}$.

Phenotypic assays. Plate-based clearing assays were performed to determine the abilities of $L$. fungicola mutants to degrade various substrates. Agar culture plugs ( $5 \mathrm{~mm}$ diameter) from transformants and wild-type strains were grown for 7 days on MM and ACWM plates supplemented with starch $(0.5 \% \mathrm{w} / \mathrm{v})$, gelatin $(0.5 \% \mathrm{w} / \mathrm{v})$, xylan $(0.5 \% \mathrm{w} / \mathrm{v})$ or skimmed-milk powder $(1.5 \% \mathrm{w} / \mathrm{v})$. Clearing zones were visualized by use of an appropriate stain: starch, iodine; gelatin, amido black; xylan, congo red. Dehydrated milk cultures did not require staining to visualize clearing zones.

Gel diffusion assays (Zou et al., 2002) for degradation of glycol chitin, a soluble, modified form of chitin, were performed using 14-day-old ACWM cultures, grown at $22{ }^{\circ} \mathrm{C}$ with gentle shaking. Mycelia were removed by centrifugation $\left(27000 \mathrm{~g}, 60 \mathrm{~min}, 4^{\circ} \mathrm{C}\right)$ and supernatants were filtered to ensure removal of cells and cell wall material. Sodium azide was added to a final concentration of $0.01 \%$ and the filtrate was concentrated using a Centricon Plus 20 (Millipore) with a $5 \mathrm{kDa}$ cutoff. Protein concentration of the retentate was determined as described by Bradford (1976) and equal protein concentrations for the retentate were used for this assay.

Infection assays were performed as previously described by Collopy et al. (2001). Harvested A. bisporus sporophores with the veil still intact had their stipes removed and were then inoculated with $L$. fungicola conidia to induce infection. Caps were inoculated with $5 \mu \mathrm{l}$ of a conidial suspension $\left(10^{6} \mathrm{ml}^{-1}\right)$ and incubated at $22^{\circ} \mathrm{C}$ for 5 days, after which, the lesion diameter was measured and recorded.
RESULTS

\section{Isolation of $L f$ pmk1}

PCR amplification using L. fungicola genomic DNA with degenerate primers designed against pmk1-like proteins yielded an approximately $420 \mathrm{bp}$ product, which was cloned using PGEMT; the sequences of three independent recombinants proved identical and database comparisons showed strong similarity to fungal $p m k 1$ homologues. Due to this high homology to other fungal MAPK genes, and particularly the pmk1-like MAPKs, the isolated L. fungicola gene was termed $L f p m k 1$. The cloned PCR fragment was used to probe a Southern blot and the presence of a single band in each lane was indicative of a single-copy gene within the L. fungicola genome (data not shown). This fragment was then used to screen a lambda genomic library and two independent plaques were purified. Inserts were subsequently excised to yield plasmids pMapKCC and pMapKFC and used as templates for sequencing by a primer-walking strategy. In total, a region of $3908 \mathrm{bp}$ was sequenced, including $1.3 \mathrm{~kb}$ of predicted promoter region, the $1.3 \mathrm{~kb}$ encoding the $L f p m k 1$ open reading frame and an additional $1.3 \mathrm{~kb}$ downstream region (GenBank accession no. AY184496).

Three introns were predicted on the basis of the expected amino acid sequence and conserved splice sequences. RTPCR was used to confirm the presence of these introns within the gene. This yielded the predicted size product of $765 \mathrm{bp}$ compared with the $964 \mathrm{bp}$ derived from genomic DNA, and the locations were subsequently confirmed by sequencing of this product. The predicted protein of 356 aa exhibits more than $90 \%$ aa identity to other fungal pmk1 homologues, as illustrated by neighbour-joining analysis (Fig. 1).

\section{Q-PCR}

Comparative transcription of $L f p m k 1$ in vegetative mycelium and infection lesions was determined using Q-PCR. Expression was detected from cultures grown in both conditions. In vegetative mycelium, the amount of $L f$ $p m k 1$ transcript when normalized to $18 \mathrm{~S}$ gave a relative value of $3.5( \pm 0.48 \mathrm{SE})$ compared with $18.8( \pm 3.40 \mathrm{SE})$ from cap lesions. These data are indicative of a more than fivefold increase in the relative expression of $L f p m k 1$ during infection.

\section{Transformation for targeted gene disruption}

The Lf pmk1 gene-specific disruption cassette was constructed in pZEJ, a pGREEN derivative containing a hygromycin resistance cassette. The two final vectors were each composed of a hygromycin B resistance cassette flanked by left and right arms of the $L f p m k 1$ gene. Both constructs contained a left arm of $1141 \mathrm{bp}$, but two different right arms of 1089 and 826 bp were used for pZMK37 and pZMK38, respectively. In addition to the disruption of the $L f p m k 1$ gene by the hygromycin resistance 


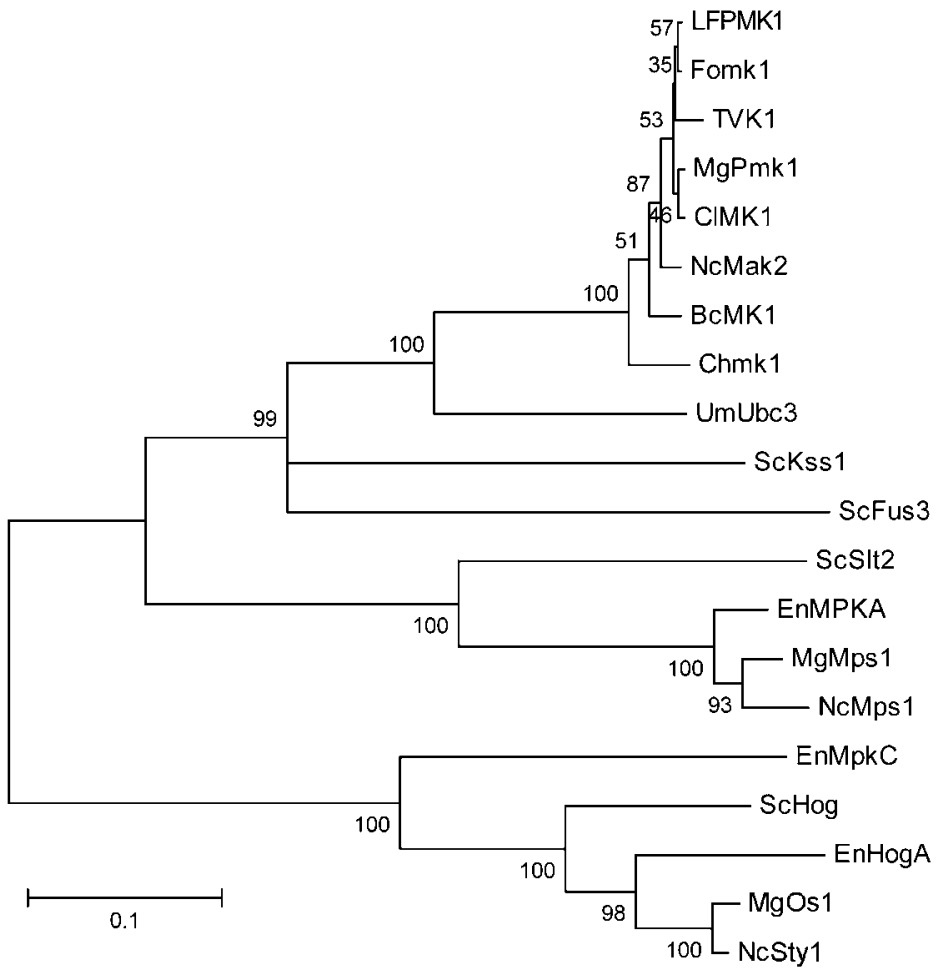

Fig. 1. Neighbour-joining phylogenetic tree of selected fungal MAPK proteins, showing the relationship of $L f p m k 1$ to the other members of the $p m k 1$-like group and to other MAPK families. LF PMK1, L. fungicola AY184496; Fomk1, F. oxysporum AAG01162; TVK1, T. virens AAO46014; MgPmk1, M. grisea ACC49521; CIMK1, Colletotrichum lagenarium AAD50496; NcMak2, Neurospora crassa AAK25816; BcMK1, B. cinereus AAG231320; Chmk1, C. heterostrophus AAF05913; UmUbc3, Ustilago maydis AAF09452; ScKss1, Saccharomyces cerevisiae AAA34882; ScFus3, S. cerevisiae AAA34613; ScSlt2, S. cerevisiae CAA41954; EnMPKA, Emericella nidulans AAD24428; MgMps1, M. grisea AAC63682; NcMps1, N. crassa XP_958040; EnMpkC, E. nidulans AAG28463; ScHog, S. cerevisiae AAA34680; EnHogA, E. nidulans AAF97243; MgOs1, M. grisea AAF09475; NcSty1, N. crassa EAA32927. Bar, 0.1 base substitutions per site.

gene cassette, a region of approximately $500 \mathrm{bp}$ of the ORF was deleted between the left and right arm flanks to ensure inactivation of the $L f p m k 1$ reading frame. Transformation of the construct was performed using Ag. tumefaciens LBA1126 containing pSoup and either the pZMK37 or pZMK38 vectors. Hygromycin-resistant lines were selected at random and screened by PCR to confirm the presence of the hygromycin transgene (Fig. 2a and b). A PCR was performed using a primer pair amplifying from within the hygromycin gene to an area outside the targeting region to confirm that homologous recombination had occurred. Three transformants 37MK1, 37MK3 (derived from pZMK37) and 38MK1 (derived from pZMK38) yielded the expected product of $1.6 \mathrm{~kb}$ (Fig. $2 \mathrm{~b}$ ). Southern analysis of these transformants showed the expected loss of wildtype band and gain of recombinant band in 37MK1 and 38MK1 (Fig. 2c), indicative of gene disruption. Strains $37 \mathrm{MK} 1$ and $38 \mathrm{MK} 1$ were therefore selected as representatives of the two knockout types for further analysis.

\section{Phenotypic effect of $L f$ pmk1 disruption on L. fungicola}

In other fungi, disruption of the pmk1-like MAPK has been reported to have a number of different phenotypic effects, including changes in virulence, growth patterns and sporulation; these phenotypes were investigated in these disrupted strains.

Growth rate comparisons between $\triangle L F M K 1$ knockouts and wild-type (150-1) L. fungicola grown on CDA, PDA or ACWM showed no significant differences, additionally there were no obvious differences in the colour of the mycelia or the colony morphology (e.g. amount of aerial hyphae). Growth rates were measured on CDA solidified with a range of agar concentrations from 0.5 to $8 \%$, but again there were no differences between the wild-type and disrupted strains, showing that the mutants were not impaired in their ability to penetrate the media. Growth rates were also assessed on a range of osmotic stabilizers including sucrose $(1 \mathrm{M}), \mathrm{KCl}(0.6 \mathrm{M}), \mathrm{NaCl}(0.9 \mathrm{M})$ and sorbitol $(1.2 \mathrm{M})$ but again there was no difference between wild-type and disrupted strains.

Spores were harvested from centrally inoculated plates after 7 days growth and were counted and measured. Conidiation rates and spore sizes were similar, indicating no apparent alteration in sporulation rates or morphology between the disruptants and the wild-type (data not shown). Although the growth of 37MK1 was slightly reduced on chitin- or xylan-modified media (Fig. 3a), this was isolate-specific and did not occur in the disruptant $38 \mathrm{MK} 1$, again indicating no obvious change in growth rates between wild-type and $\triangle L F M K 1$ mutants.

There have been reports of altered levels of secreted enzymes associated with disruption of pmk1-like MAPKs (e.g. Lev \& Horwitz, 2003). We used plate-based assays to monitor production of amylase and protease. In our clearing zone experiments, there were no significant differences in the rate of growth or size of clearing zone on starch plates, indicating that amylase activity was unaffected (Fig. 3b). Likewise, there was no difference in protease secretion as indicated by clearing zones on either 
(a)

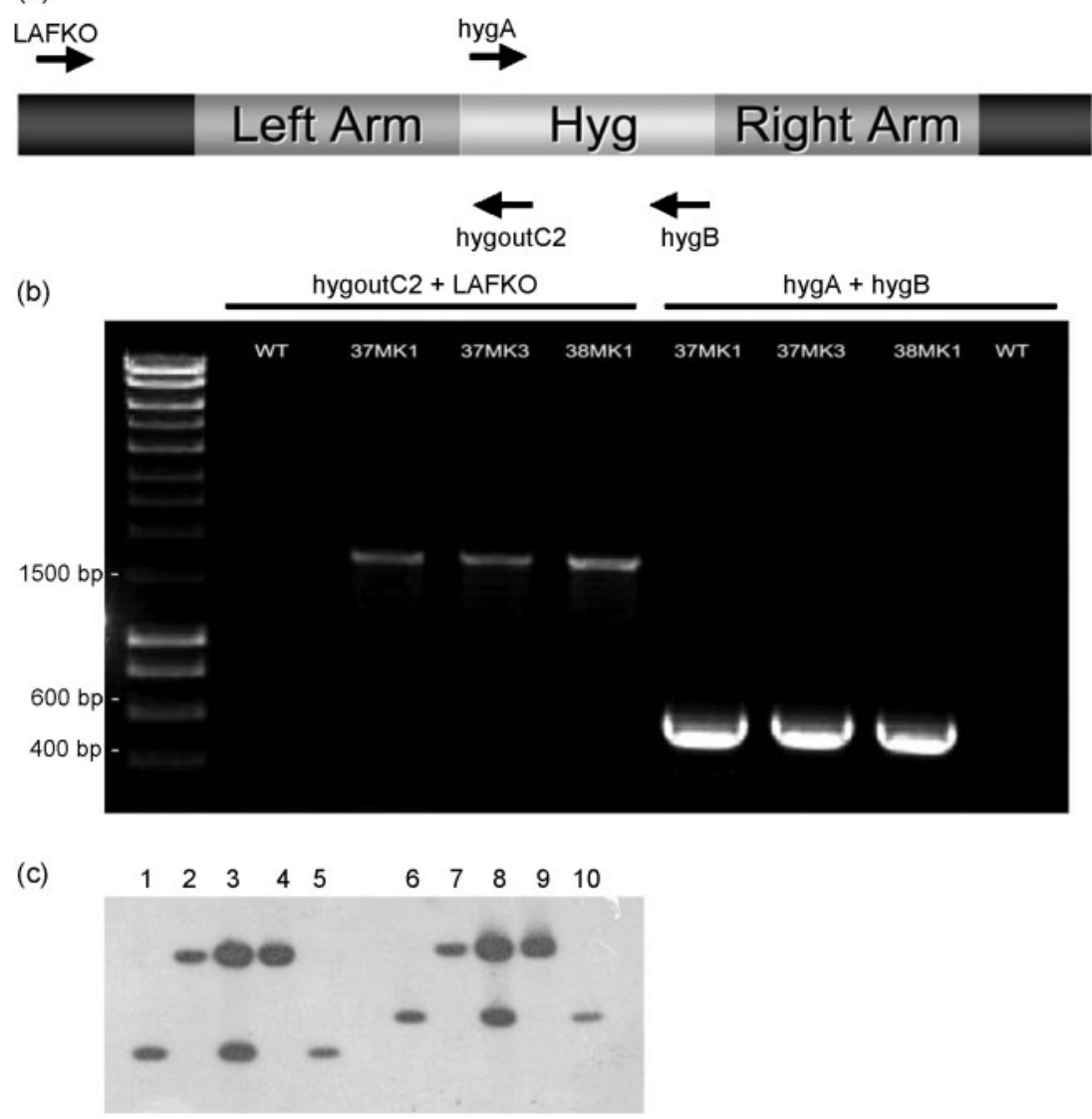

Fig. 2. (a) Schematic showing primers used for confirmation of transformation and disruption of $L f p m k 1$. Primers hygA and hygB were used to confirm the presence of the hygromycin resistance cassette among potential $L$. fungicola transformants. Primers LAFKO and hygoutC2 were used to confirm homologous integration of the gene disruption cassette into LFMK1. (b) PCR products amplified using LAFKO with hygoutC2 (to confirm homologous integration) and hygA with hygB (to confirm genuine hygromycin resistance). WT lanes are the results of PCR from 150-1 (wildtype) DNA. 37MK1, 37MK3 and 38MK1 are PCR results from probable deletion strains. The left lane contains a molecular marker (Hyperladder I, Bioline). (c) Southern blot analysis. Lanes $1-5$ and $6-10$ contain digested DNA of 150-1 (wild-type), 37MK1, $37 \mathrm{MK} 3$ and $38 \mathrm{MK} 1$, and a control transformant, cut with Bg/ll and Sacl, respectively, and probed with the right flank sequence. 37MK1 and $38 \mathrm{MK} 1$ show the loss of the wild-type band $(1.1 \mathrm{~kb}$ and $1.4 \mathrm{~kb}$ for $\mathrm{Bg} / \mathrm{ll}$ and Sacl) and gain of recombinant bands $(2.1 \mathrm{~kb}$ and $2.2 \mathrm{~kb}$ for $\mathrm{Bg} / \mathrm{ll}$ and Sacl) indicative of gene disruption. 37MK3 shows both the wild-type and recombinant bands. skimmed-milk- or gelatin-modified media (Fig. 3b). There was also no significant difference between wild-type and disruption transformants in the diffusible chitinase activity assays performed on liquid media in which L. fungicola had been grown (data not shown).

\section{Virulence of $\mathbf{L f}$ pmk1 mutants}

Detached cap bioassays, which we have previously used to assess virulence of L. fungicola transgenic lines (Amey et al., 2003), were deployed to compare Lf pmkl disruption transformants with the wild-type. No significant differences were observed during pathogenicity assays using conidia suspensions on A. bisporus detached mushrooms. In control inoculations, wild-type L. fungicola conidia resulted in necrotic lesions, and sterile DI water produced no lesions. All lesions appeared the same as the wild-type, with a sunken appearance and brown coloration. There was no difference in lesion diameters (Fig. 4) or the onset of development of lesions formed by wild-type and $L f p m k 1$ disruption transformants.

\section{DISCUSSION}

The development of cap lesions and other dry bubble symptoms caused by the mushroom pathogen L. fungicola, are considered to be the results of both physical and chemical damage to host tissue (Dragt et al., 1996; Calonje et al., 1997). It could be expected that the fungal-fungal interaction requires mechanisms to detect suitable host material and that a signal transduction process triggers the expression of appropriate virulence factors, as has been well characterized in numerous fungal-plant pathogens. The recent development of a gene disruption strategy (Amey et al., 2003) for L. fungicola affords an opportunity to study the mechanisms of mycoparasitism in this intriguing pathosystem (Amey et al., 2003) and to elucidate the roles of signal transduction pathways. Degenerate PCR was successfully employed to isolate a portion of $L f p m k 1$ and subsequent library screening and analysis led to the isolation of the entire gene. This is predicted to encode a MAPK with a molecular mass of $41.2 \mathrm{kDa}$ which displays high levels of similarity to the pmk1-like group of MAPKs. As would be expected from a gene that might potentially play a role in pathogenicity, $L f p m k 1$ transcripts were substantially upregulated during infection of $A$. bisporus.

Agrobacterium-mediated transformation permitted recovery of transformants with disrupted $L f p m k 1$ sequences. Disruption transformants did not exhibit altered growth rates or secreted enzyme profiles, which is in contrast with observations in other fungi, in which sporulation can be impaired or secreted enzyme profiles can be altered (e.g. Di 

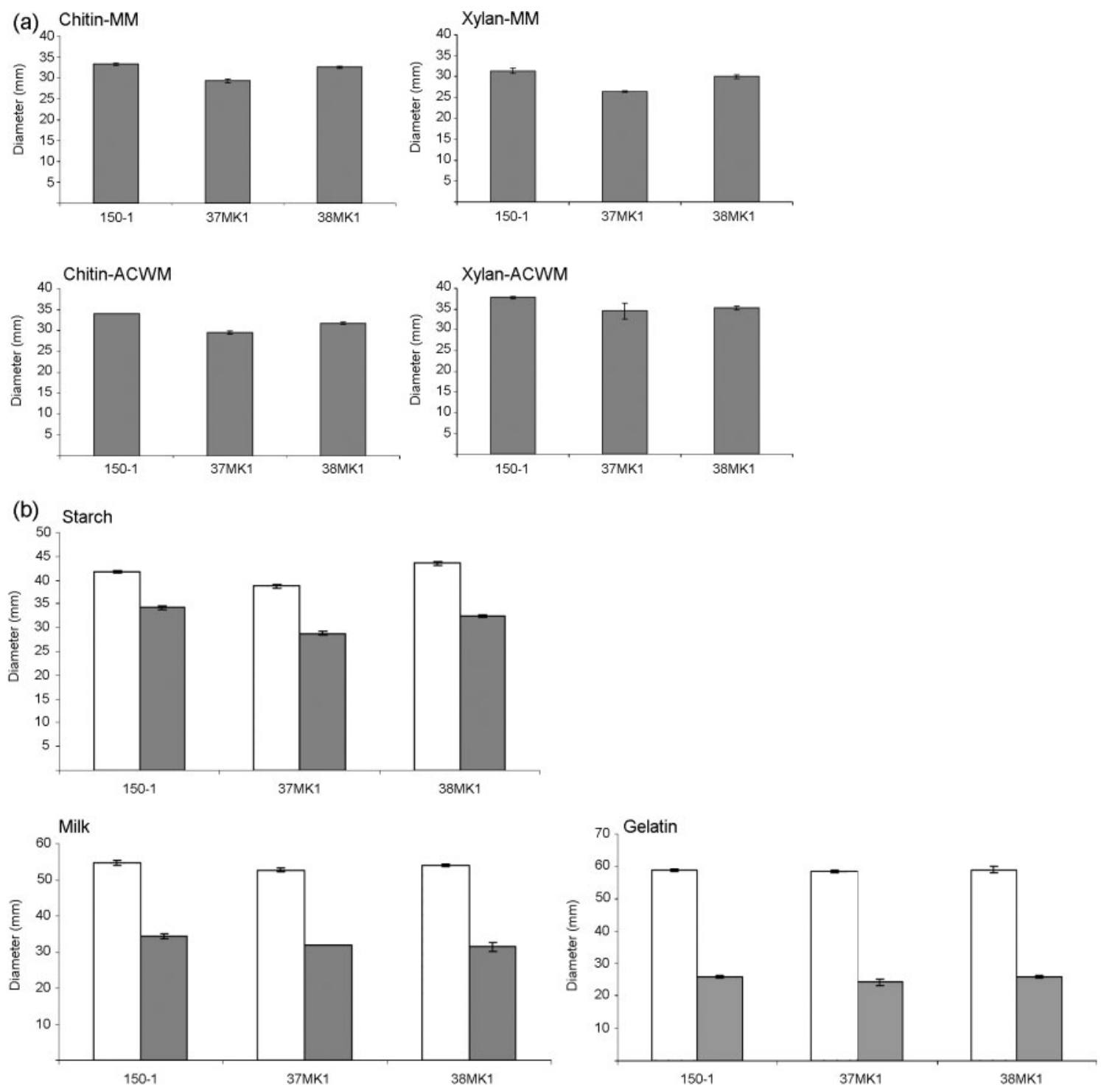

Fig. 3. (a) Colony diameter of wild-type and $L f$ pmk1 disrupted strains $37 \mathrm{MK} 1$ and $38 \mathrm{MK} 1$ after 5 days growth on various media, showing no changes in growth rate. (b) Clearing zone (empty bars) and colony diameters (solid bars) after 5 days growth on starch, milk or gelatin plates for wild-type and $L f$ pmk1 disrupted strains $37 \mathrm{MK} 1$ and $38 \mathrm{MK} 1$, showing no difference in amylase or protease secretion.

Pietro et al., 2001; Lev \& Horwitz, 2003; Cho et al., 2007). The pathogenicity of disruption transformants was also indistinguishable from the wild-type in terms of phenotype or virulence, which is in stark contrast with the situation in plant-pathogenic fungi where all previous reports of pmk1like MAPK disruptions have resulted in either reduction or elimination of virulence.

Signal transduction pathways are thought to play integral roles in pathogenesis and the establishment of infection in a number of host-pathogen interactions (Ruiz-Roldan et al., 2001). Numerous studies have demonstrated that disruption of MAPK homologues in various plant pathogens interferes with signal transduction pathways that are integral to pathogenesis and typically result in decreased virulence (Xu \& Hamer, 1996; Xu et al., 1998; Lev et al., 1999; Muller et al., 1999; Takano et al., 2000; Zheng et al., 2000; Mayorga \& Gold, 2001; Ruiz-Roldan et al., 2001). Such pathogenicity determinants are not always specific to the interaction of a plant pathogen with one particular host. Disruption of BMK1 in B. cinerea or VMK1 in $V$. dahliae resulted in severely reduced virulence on a number of different host plants (Zheng et al., 2000; Rauyaree et al., 2005). Such results suggest that the MAPK signalling pathway may have a conserved role in plant-pathogenic fungi despite the absence of an intimate host-pathogen interaction. Although MAPK signalling pathways have a universal role in displaying full virulence in fungal 


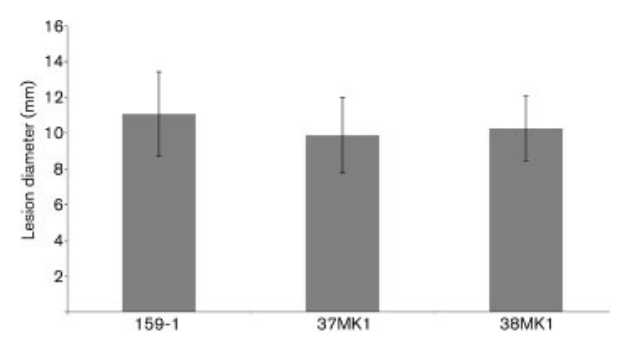

Fig. 4. Mean diameter $(n=20)$ of cap lesions on $A$. bisporus 5 days post-inoculation with wild-type (150-1) or an Lf pmk1 disruption transformant (37MK1 and 38MK1). There was no significant difference in virulence between the disruption transformants and the wild-type.

pathogenesis against plant hosts, $f m k 1$ mutants of F. oxysporum displayed normal virulence in immunorepressed mice (Ortoneda et al., 2004), whilst showing reduced virulence in planta. Whilst this is not a natural situation, it does show that $f m k 1$ was not required to support growth on such a host, although such animals are also subject to infection by other microbes not usually regarded as pathogens.

Trichoderma species, which are commonly used as biocontrol agents to reduce the effects of fungal plant pathogens, exhibit various effects when specific pmkl-like MAPKs are disrupted; reduced biological control was reported against Rhizoctonia solani and Sclerotiorum rolfsii for tmkA mutants (Mukherjee et al., 2003), whereas increased control was seen for Trichoderma virens tvk 1 mutants against $R$. solani and Pythium ultimum, but with more variable behaviour reported against other target fungi (Mendoza-Mendoza et al., 2003). Additional, indirect, effects on apparent biocontrol activity, such as the induction of plant resistance pathways (Viterbo et al., 2005; Reithner et al., 2007), have further complicated the interpretation of gene disruptions in other systems. Collectively, these observations indicate that the roles of pmk1-like MAPKs in other pathogenic interactions can be more diverse than those found in fungal-plant interactions.

The observation that $L f p m k 1$ disruptants do not exhibit reduced virulence suggests that the signalling pathway does not play a direct role in pathogenicity or sensing of environmental cues from its fungal host. Alternatively, it is possible that a different MAPK pathway has evolved to regulate virulence in L. fungicola or to act as a substitute for it in $L f p m k 1$ mutants, but we saw no evidence for a similar gene following Southern blot analysis. L. fungicola does not obviously parasitize vegetative hyphae of Agaricus (in vitro) but does attack developing mushrooms, indicating that there must be a detection mechanism that can differentiate between these two host physiologies. Recent investigations into the recognition and binding of $L$. fungicola on A. bisporus mushrooms have identified a lectin present in fruit bodies that is not present in A. bisporus mycelium (Bernardo et al., 2004). A glucogalactomannan on the surface of L. fungicola specifically complements this lectin and may explain the inability of L. fungicola to infect A. bisporus mycelium. In this research, we investigated the ability of L. fungicola to cause cap lesions on maturing mushrooms, as these are the symptoms of most economic significance due to loss of visual quality of the resulting crop. Different L. fungicola isolates vary in their abilities to cause the three symptoms of disease and it is possible that different regulatory pathways are activated with other symptoms.

Recent publications have reported the isolation of L. fungicola from nematodes (Gené et al., 2005) along with numerous reports that L. longisporum ( $V$. lecanii) can be used for the biological control of not only insects but also mildews and rusts (e.g. Jun-Kim et al., 2007; Spencer \& Atkey, 1981). It would be interesting to investigate whether disrupting $p m k 1$ homologues in L. longisporum results in altered pathogenicity and to determine whether the gene plays a significant role in other fungal-invertebrate and/or mycopathogen pathosystems.

\section{ACKNOWLEDGEMENTS}

The authors would like to express thanks to Monaghan Middlebrook Mushrooms (Langford, Bristol) for supplying mushrooms for the bioassays. Research at Bristol and Warwick was funded by DEFRA grants HH1756SMU and HH3220SMU.

\section{REFERENCES}

Amey, R. C., Athey-Pollard, A., Burns, C., Mills, P. R., Bailey, A. \& Foster, G. D. (2002). PEG-mediated and Agrobacterium-mediated transformation in the mycopathogen Verticillium fungicola. Mycol Res 106, 4-11.

Amey, R. C., Mills, P. R., Bailey, A. \& Foster, G. D. (2003). Investigating the role of a Verticillium fungicola beta-1,6-glucanase during infection of Agaricus bisporus using targeted gene disruption. Fungal Genet Biol 39, 264-275.

Amey, R. C., Athey-Pollard, A., Mills, P. R., Foster, G. D. \& Bailey, A. M. (2007). Investigations into the taxonomy of the mushroom pathogen Verticillium fungicola and its relatives based on analysis of nitrate reductase and ITS sequences. Mikrobiologiia 76, 853-864.

Bernardo, D., Cabo, A. P., Novaes-Ledieu, M. \& Mendoza, C. G. (2004). Verticillium disease or "dry bubble" of cultivated mushrooms: the Agaricus bisporus lectin recognizes and binds the Verticillium fungicola cell wall glucogalactomannan. Can J Microbiol 50, 729-735.

Bonnen, A. M. \& Hopkins, C. (1997). Fungicide resistance and population variation in Verticillium fungicola, a pathogen of the button mushroom Agaricus bisporus. Mycol Res 101, 89-96.

Bradford, M. M. (1976). A rapid and sensitive method for the quantitation of microgram quantities of protein utilizing the principle of protein-dye binding. Anal Biochem 72, 248-254.

Calonje, M., García Mendoza, C., Galan, B. \& Novaes-Ledieu, M. (1997). Enzymic activity of the mycoparasite Verticillium fungicola on Agaricus bisporus fruit body cell walls. Microbiology 143, 29993006 . 
Cho, Y., Cramer, R. A., Jr, Kim, K.-H., Davis, J., Mitchell, T. K., Figuli, P., Pryor, B. M., Lemasters, E. \& Lawrence, C. B. (2007). The fus3/Kss1 MAP kinase homolog Amk1 regulates the expression of genes encoding hydrolytic enzymes in Alternaria brassicicola. Fungal Genet Biol 44, 543-553.

Chrysayi-Tokousbalides, M., Kastanias, M. A., Phillippoussis, A. \& Diamantopoulou, P. (2007). Selective fungitoxicity of famoxadone, tebuconazole and trifloxystrobin between Verticillium fungicola and Agaricus bisporus. Crop Prot 26, 469-475.

Clarke, D. L., Woodlee, G. L., McClelland, C. M., Seymour, T. S. \& Wickes, B. L. (2001). The Cryptococcus neoformans STE11 alpha gene is similar to other fungal mitogen-activated protein kinase kinase kinase (MAPKKK) genes but is mating type specific. Mol Microbiol 40, 200-213.

Collopy, P. D., Largeteau-Mamoun, M. L., Romaine, C. P. \& Royse, D. J. (2001). Molecular phylogenetic analyses of Verticillium fungicola and related species causing dry bubble disease of the cultivated button mushroom, Agaricus bisporus. Phytopathology 91, 905-912.

Dickman, M. B. \& Yarden, O. (1999). Ser/Thr kinases and phosphatases in filamentous fungi. Fungal Genet Biol 26, 99-117.

Di Pietro, A., Garcia-Maceira, F. I., Meglecz, E. \& Roncero, M. I. G. (2001). A MAP kinase of the vascular wilt fungus Fusarium oxysporum is essential for root penetration and pathogenesis. Mol Microbiol 39, $1140-1152$

Dragt, J. W., Geels, F. P., De Bruijn, W. C. \& van Griensven, L. J. L. D. (1996). Intracellular infection of the cultivated mushroom Agaricus bisporus by the mycoparasite Verticillium fungicola var. fungicola. Mycol Res 100, 1082-1086.

Gené, J., Verdejo-Lucas, S., Stchigel, A. M., Sorribas, F. J. \& Guarro, J. (2005). Microbial parasites associated with Tylenchulus semipenetrans in citrus orchards of Catalonia, Spain. Biocontrol Sci Technol 15, 721731.

Hellens, R. P., Edwards, E. A., Leyland, N. R., Bean, S. \& Mullineaux, P. M. (2000). pGreen: a versatile and flexible binary vector for Agrobacterium-mediated plant transformation. Plant Mol Biol 42, 819-832.

Hooykaas, P. J. J., Roobol, C. \& Schilperoort, R. A. (1979). Regulation of the transfer of Ti-plasmids of Agrobacterium tumefaciens. J Gen Microbiol 110, 99-109.

Johnson, Z. E. (2006). Non-ribosomal peptide synthases of Mycosphaerella graminicola. PhD thesis, University of Bristol, UK.

Jun Kim, J., Goettel, M. S. \& Gillespie, D. R. (2007). Potential of Lecanicillium species for dual microbial control of aphids and the cucumber powdery mildew fungus Sphaerotheca fuligina. Biol Control 40, 327-332.

Keon, J. \& Hargreaves, J. (1998). Isolation and heterologous expression of a gene encoding 4-hydroxyphenylpyruvate dioxygenase from the wheat leaf-spot pathogen, Mycosphaerella graminicola. FEMS Microbiol Lett 161, 337-343.

Kültz, D. (1998). Phylogenetic and functional classification of mitogen- and stress-activated protein kinases. J Mol Evol 46, 571-588.

Kumar, S., Tamura, D. \& Nei, M. (2004). MEGA3: integrated software for Molecular Evolutionary Genetics Analysis and sequence alignment. Brief Bioinform 5, 150-163.

Lev, S. \& Horwitz, B. A. (2003). A mitogen-activated protein kinase pathway modulates the expression of two cellulase genes in Cochliobolus heterostrophus during plant infection. Plant Cell 15, 835-844.

Lev, S., Sharon, A., Hadar, R., Ma, H. \& Horowitz, B. A. (1999). A mitogen-activated protein kinase of the corn leaf pathogen Cochliobolus heterostrophus is involved in conidiation, appressorium formation, and pathogenicity: diverse roles for mitogen-activated protein kinase homologs in foliar pathogens. Proc Natl Acad Sci U S A 96, 13542-13547.

Mayorga, M. E. \& Gold, S. E. (2001). The $u b c 2$ gene of Ustilago maydis encodes a putative novel adaptor protein required for filamentous growth, pheromone response and virulence. Mol Microbiol 41, 13651379.

Mendoza-Mendoza, A., Pozo, M. J., Grzegorski, D., Martinez, P., Garcia, J. M., Olmedo-Monfil, V., Cortes, C., Kenerley, C. \& HerreraEstrella, A. (2003). Enhanced biocontrol activity of Trichoderma through inactivation of a mitogen-activated protein kinase. Proc Natl Acad Sci U S A 100, 15965-15970.

Mey, G., Oesler, B., Lebrun, M.-H. \& Tudzynski, P. (2002). The biotrophic, non-appressorium-forming grass pathogen Claviceps purpurea needs a Fus3/Pmk1 homologous mitogen-activated protein kinase for colonization of rye ovarian tissue. Mol Plant Microbe Interact 15, 303-312.

Mills, P., Thomas, J., Sergeant, M., Costa, A., Collopy, P. D., Bailey, A., Foster, G. \& Challen, M. (2008). Interactions between Agaricus bisporus and the pathogen Verticillium fungicola. In Stress in Yeasts and Filamentous Fungi, pp. 1-17. Edited by S. V. Avery, M. Stratford \& P. Van West. London, UK: Academic Press.

Mukherjee, P. K., Latha, J., Hadar, R. \& Horwitz, B. A. (2003). TmkA, a mitogen-activated protein kinase of Trichoderma virens, is involved in bio-control properties and repression of conidiation in the dark. Eukaryot Cell 2, 446-455.

Muller, P., Aichinger, C., Feldbrugge, M. \& Kahmann, R. (1999). The MAP kinase Kpp2 regulates mating and pathogenic development in Ustilago maydis. Mol Microbiol 34, 1007-1017.

Nishida, E. \& Gotoh, Y. (1993). The MAP kinase cascade is essential for diverse signal transduction pathways. Trends Biochem Sci 18, 128131.

Novaes-Ledieu, M. \& Mendoza, C. G. (1981). The cell walls of Agaricus bisporus and Agaricus campestris fruiting body hyphae. Can J Microbiol 27, 779-787.

Ortoneda, M., Guarro, J., Madrid, M. P., Caracuel, Z., Roncero, M. I. G., Mayayo, E. \& Di Pietro, A. (2004). Fusarium oxysporum as a multihost model for the genetic dissection of fungal virulence in plants and mammals. Infect Immun 72, 1760-1766.

Park, S. H., Zarrinpar, A. \& Lim, W. A. (2003). Rewiring MAP kinase pathways using alternative scaffold assembly mechanisms. Science 299, 1061-1064.

Park, S. M., Choi, E. S., Kim, M. J., Cha, B. J., Yang, M. S. \& Kim, D. H. (2004). Characterization of HOG1 homologue, CpMK1, from Cryphonectria parasitica and evidence for hypovirus-mediated perturbation of its phosphorylation in response to hypertonic stress. Mol Microbiol 51, 1267-1277.

Rauyaree, P., Ospina-Giraldo, M. D., Kang, S., Bhat, R. G., Subbarao, K. V., Grant, S. J. \& Dobinson, K. F. (2005). Mutations in VMK1, a mitogen-activated protein kinase gene, affect microsclerotia formation and pathogenicity in Verticillium dahliae. Curr Genet 48, 109116.

Reithner, B., Schumacher, R., Stoppacher, N., Pucher, M., Brunner, K. \& Zeilinger, S. (2007). Signaling via the Trichoderma atroviride mitogen-activated protein kinase Tmk1 differentially affects mycoparasitism and plant protection. Fungal Genet Biol 44, 1123-1133.

Ruiz-Roldan, M. C., Maier, F. J. \& Schafer, W. (2001). PTK1, a mitogen-activated-protein kinase gene, is required for conidiation, appressorium formation, and pathogenicity of Pyrenophora teres on barley. Mol Plant Microbe Interact 14, 116-125.

Schaeffer, H. J. \& Weber, M. J. (1999). Mitogen-activated protein kinases: specific messages from ubiquitous messengers. Mol Cell Biol 19, 2435-2444. 
Spencer, D. M. \& Atkey, P. T. (1981). Parasitic effects of Verticillium lecanii on two rust fungi. Trans Br Mycol Soc 77, 535-542.

Takano, Y., Kikuchi, T., Kubo, Y., Hamer, J. E., Mise, K. \& Furusawa, I. (2000). The Colletotrichum lagenarium MAP kinase gene CMK1 regulates diverse aspects of fungal pathogenesis. Mol Plant Microbe Interact 13, 374-383.

Viterbo, A., Harel, M., Horwitz, B. A., Chet, I. \& Mukherjee, P. K. (2005). Trichoderma mitogen-activated protein kinase signalling is involved in induction of plant systemic resistance. Appl Environ Microbiol 71, 6241-6246.

Xu, J. R. (2000). MAP kinases in fungal pathogens. Fungal Genet Biol 31, 137-152.

Xu, J. R. \& Hamer, J. E. (1996). MAP kinase and cAMP signaling regulate infection structure formation and pathogenic growth in the rice blast fungus Magnaporthe grisea. Genes Dev 10, 26962706.

Xu, J.-R., Staiger, C. J. \& Hamer, J. E. (1998). Inactivation of the mitogen-activated protein kinase Mps1 from the rice blast fungus prevents penetration of host cells but allows activation of plant defense responses. Proc Natl Acad Sci U S A 95, 12713-12718.

Zare, R. \& Gams, W. (2001). A revision of Verticillium section Prostrata. VI. The genera Lecanicillium and Simplicillium gen. nov. Nova Hedwigia 73, 1-50.

Zare, R. \& Gams, W. (2008). A revision of the Verticillium fungicola species complex and its affinity with the genus Lecanicillium. Mycol Res 112, 811-824.

Zhao, X., Mehrabi, R. \& Xu, J.-R. (2007). Mitogen-activated protein kinase pathways and fungal pathogenesis. Eukaryot Cell 6, 1701-1714.

Zheng, L., Campbell, M., Murphy, J., Lam, S. \& Xu, J.-R. (2000). The BMP1 gene is essential for pathogenicity in the gray mold fungus Botrytis cinerea. Mol Plant Microbe Interact 13, 724-732.

Zou, X., Nonogaki, H. \& Welbaum, G. E. (2002). A gel diffusion assay for visualization and quantification of chitinase activity. Mol Biotechnol 22, 19-23.

Edited by: N. L. Glass 